\title{
Participando y expandiendo nuestra Revista
}

Dra. Lidia G. Loterzo

Coeditora de la Revista de Ortopedia y Traumatología de la Asociación Argentina de Ortopedia y Traumatología

Maestrando en Docencia Universitaria

Hospital Central de San Isidro "Dr. Melchor Ángel Posse”

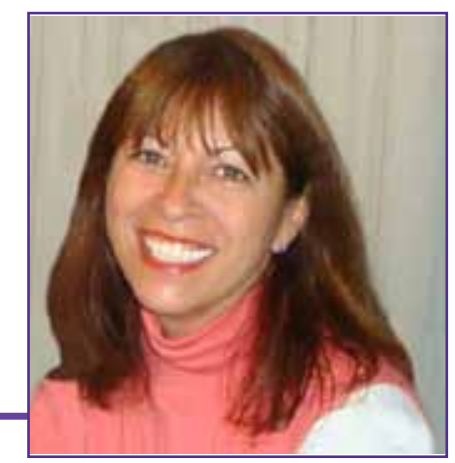

Estimados lectores:

Nos encontramos, una vez más, al terminar un año de trabajo editorial. En algún momento, expusimos que, en la Revista, se materializa el artículo II del estatuto de la AAOT que expresa: "fomentando la actividad científica y dándola a conocer a sus asociados". También aclaramos la importancia de todos y cada uno de los actores (autor, revisor y Comité Editorial) en el flujo editorial para que llegue a publicarse la actividad científica llevada a cabo por un autor. Por lo tanto, cada asociado tiene en sus manos tanto la construcción de esta herramienta, como el modo de usarla, dicho esto, las herramientas se hacen con el fin de ayudarnos en nuestra práctica a resolver los problemas que se nos presentan diariamente.

Por lo tanto, al llegar estos tiempos particulares, la Revista nos encontró preparados para realizar la innovación que exige esta contemporaneidad, para "dar a conocer a sus asociados" y a los lectores nacionales e internacionales que busquen actualización de temas de su práctica. Esto es dar la visibilidad pertinente de los contenidos de la Revista, expandiéndola de manera apropiada.

Esto nos llevó a implementar la difusión de dichos contenidos en las redes, como agregar los podcasts en nuestra página institucional. Son todos canales actuales que suman a la divulgación científica de calidad.

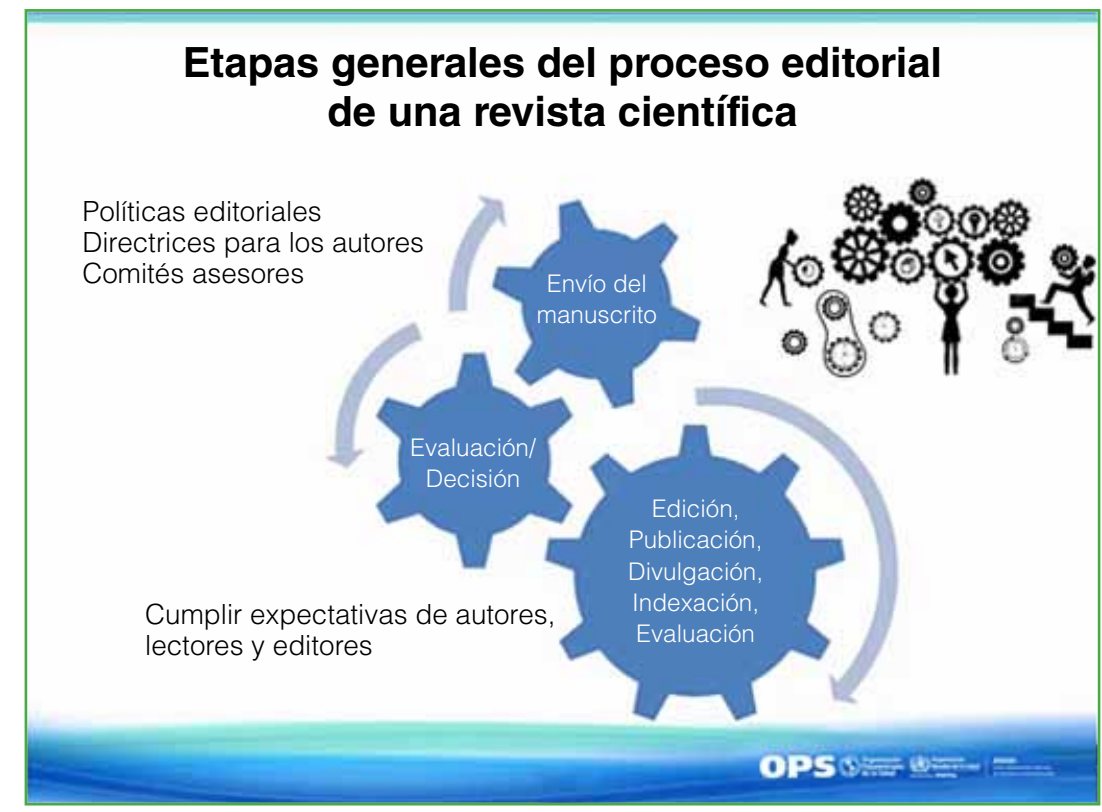

Dra. LIDIA G. LOTERZO • lidiagloterzo@ gmail.com

https://orcid.org/0000-0001-5465-1747

Cómo citar este artículo: Loterzo LG. Participando y expandiendo nuestra Revista. Rev Asoc Argent Ortop Traumatol 2020;85(4):301-302. https://doi.org/10.15417/issn. 1852-7434.2020.85.4.1213 
Para fomentar esa calidad científica, inclusive estamos llevando a cabo el reconocimiento a los revisores que entienden que su tarea está ligada íntimamente a que fueron o son autores de manuscritos que llegaron o no a la publicación. Encargados de enriquecer los manuscritos destacando fortalezas y despojados de opiniones que no sirvan para mejorar las debilidades de dicho manuscrito.

Tenemos presente, lector, autor, revisor y el comité, que la palabra escrita es la herramienta básica del pensamiento para comunicar nuestras ideas y actividades. Esa comunicación implica los resultados de la actividad científica, teórica y práctica, llevada a cabo, indisolublemente relacionada con la escritura, es el instrumento para acrecentar el propio saber y el progreso de la ciencia.

En este camino, damos por finalizado este año de trabajo editorial agradeciendo a cada uno de los actores que hace posible la Revista e iniciaremos otro año esperando nuevas sorpresas de nuestra Revista. 